\title{
Use of a Computerized Decision Support System for Primary and Secondary Prevention of Work-Related MSD Disability
}

\author{
Sarah K. Womack ${ }^{1,2}$ and Thomas J. Armstrong ${ }^{1}$
}

The present study evaluates the effectiveness of a decision support system used to evaluate and control physical job stresses and prevent re-injury of workers who have experienced or are concerned about work-related musculoskeletal disorders. The software program is a database that stores detailed job information such as standardized work data, videos, and upper-extremity physical stress ratings for over 400 jobs in the plant. Additionally, the database users were able to record comments about the jobs and related control issues. The researchers investigated the utility and effectiveness of the software by analyzing its use over a 20-month period. Of the 197 comments entered by the users, $25 \%$ pertained to primary prevention, $75 \%$ pertained to secondary prevention, and 94 comments $(47.7 \%)$ described ergonomic interventions. Use of the software tool improved primary and secondary prevention by improving the quality and efficiency of the ergonomic job analysis process.

KEY WORDS: musculoskeletal disorders; decision support systems; secondary prevention.

\section{INTRODUCTION}

Disability due to work-related musculoskeletal disorders (WMSDs) in manufacturing organizations is a common problem. According to the Bureau of Labor Statistics (1), there were 1,436,200 lost workday injuries and illnesses in $2002 ; 45.2 \%$ of those cases involved musculoskeletal sprains, strains, carpal tunnel syndrome, and tendonitis. The task at hand in today's labor intensive industries is to continuously reduce WMSD risk exposure, e.g., high repetition, low recovery time, forceful exertions, mechanical stress, and awkward postures $(2,3)$ to acceptable levels and provide disabled workers reasonable and appropriate accommodations by properly evaluating and matching worker capacity and job demands. The tradition of systematic job analysis at the micro level (e.g., work elements and motions), pioneered by the Gilbreths (4), is still relevant in the improvement of jobs and development of accommodations for workers with limitations. The analysis of work methods is standard

\footnotetext{
${ }^{1}$ Center for Ergonomics, Department of Industrial and Operations Engineering, College of Engineering, University of Michigan, Ann Arbor, Michigan.

${ }^{2}$ Correspondence should be directed to Sarah K. Womack, PhD Student, Industrial and Operations Engineering, University of Michigan, Ann Arbor, Michigan 48109; e-mail: womacks@umich.edu.
} 
procedure for engineering safe work and eliminating the gaps that exist between worker capacity and job demands (5-8) - this requires gathering detailed job data, which can be burdensome in large manufacturing plants. Toward this end, a computerized decision support system was developed to make job information readily available to those involved in the improvement and accommodation process (8).

Decision support system (DSS) applications are widely used in management science and could prove useful in ergonomics as well. One trend in DSS that has greatly advanced with improvements in information technology is spreadsheet-based decision support systems, designed to help managers solve semistructured and unstructured problems $(9,10)$. The decision support software in this study was a spreadsheet-based database program written in Microsoft Excel ${ }^{\mathrm{TM}}$, which was already used at the company and is widely used across other companies (9). It was designed specifically for the site, but is adaptable to other manufacturing plants with relatively stable work patterns.

This study evaluates the applicability of the DSS in the process of identifying, evaluating, and controlling risk factors in the plant and the effectiveness of the tool on the ergonomic team's response to medical cases and supervisor and/or worker concerns. This report will discuss assessment in terms of the usability of the software and how it aided in the overall process of evaluating and controlling ergonomic risk exposure. The organization of this report is as follows: a brief discussion of the DSS tool and the worksite, a description of the users and alternative software tools, a description of the research and data collection methods, and presentation and discussion of the results.

\section{BACKGROUND}

A database was initially designed to maintain a record of jobs in a study of WMSDs at an automobile assembly plant in the fourth quarter of 2001. The plant ergonomists indicated that the job data would help them with their analysis of jobs and control of WMSDs. As a result, the database was enhanced with a graphical user interface (GUI) and other features to facilitate storing and retrieving job data. The database was populated with data on over 470 (out of approximately 500) jobs in the assembly plant.

The assembly plant built small trucks in a 2.1 million square foot facility. There were over 500 on- and offline assembly jobs in the plant and the workforce of approximately 2,580 union employees was divided over two production and one maintenance shifts. The production rate was leveled at approximately 60 vehicles per $h$. The average age of the workers was 47.7 years of which $23.8 \%$ were women. As of September 2003, the production line in the study was retired and the succeeding production line was located at a new facility adjacent to the old plant.

The ergonomists at the plant were three union and management employees (UMETs) responsible for secondary and primary prevention of ergonomic injuries. Their primary job analysis tool used for prevention was the Risk Factor Checklist, RFC (11). It served as a first-level screening tool to identify exposure levels of [nonneutral] posture, vibration, lifting, repetition, and force; to determine if a job required corrective action (from an initial analysis); and to determine if a job was corrected (in the re-analysis).

The standard procedure for identifying, evaluating, and assessing ergonomic stressors required gathering detailed job information from multiple sources, which resulted in a considerable amount of paper handling and traveling between the ergonomics office, industrial 


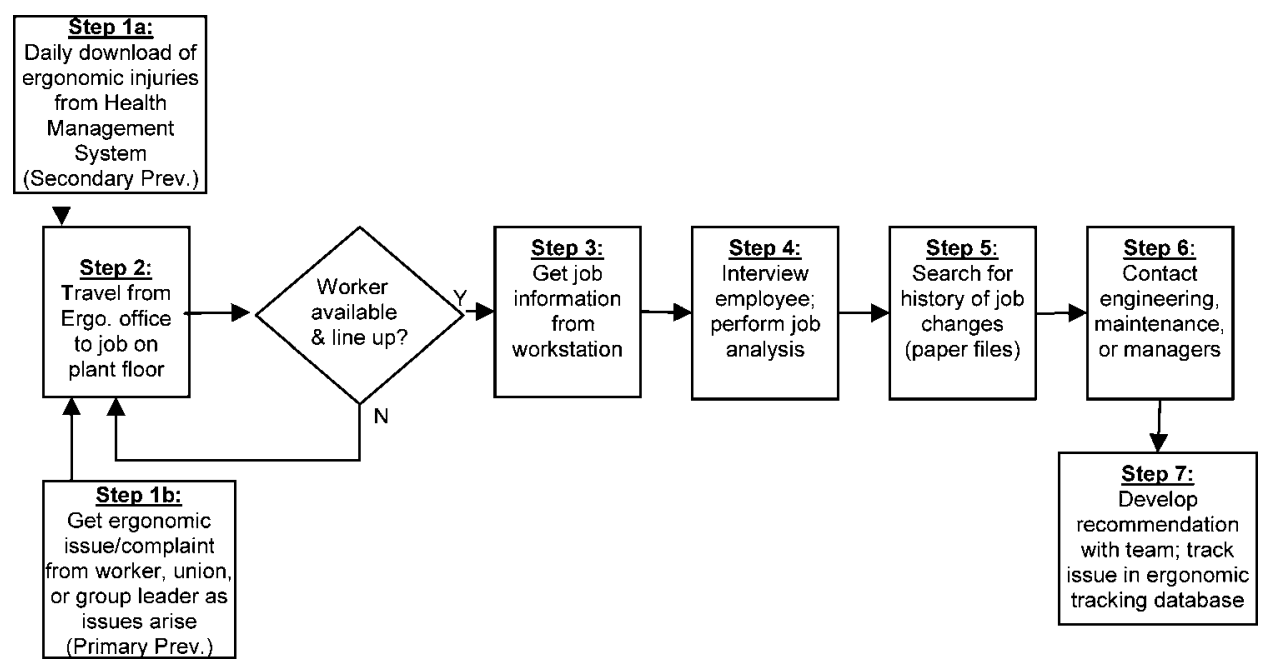

Fig. 1. Ergonomic evaluation process before implementation of the decision support system.

engineering office, and plant floor. Figure 1 represents the high-level steps involved in the process. After receiving a request to evaluate a job (Fig. 1, Step 1a and 1b) from medical, worker, or supervisor, the UMET would go to the job (Fig. 1, Step 2) to collect information (Fig. 1, Step 3) such as work methods, equipment, layout, and work instructions (posted near the job). If the line was operating and the worker was available, the UMET would interview the worker (Fig. 1, Step 4) and evaluate the observable risk factors using the company's primary analysis tool, the Risk Factor Checklist (11). In some cases, the evaluator would take pictures or videos for further analysis and/or search for historical job information (Fig. 1, Step 5) to identify any changes that may have led to increased risk. After the initial analysis the UMET would work independently or collectively to discuss the evaluation and prevention measures with engineering, maintenance, and/or the job manager (Fig. 1, Step 6). After a recommendation was reached on the prevention or intervention, the issue would be logged into the company's ergonomic database system. In some cases, follow-up evaluations were performed.

Some of the job information (e.g., standard work elements, standard time data, tools required, etc.) the UMETs retrieved from worker's job area was already in the company's mainframe database. The DSS integrated much of this and other information into one centralized source to create the job database. The job database was differed from the other companywide health management databases in that it was not password restricted, which allowed the union UMETs access to the information; it tracked job changes over time; and it provided a virtual work environment for analyzing WMSD risk exposure. Figure 2 shows the graphical user interface (GUI) of the software. The main features evaluated and presented in the Results Section include:

- graphical user interface (GUI) in the Windows ${ }^{\mathrm{TM}}$ environment

- video clips of representative cycles of the selected job and in some cases, multiple videos showing multiple views (see Fig. 2, section $G$ ) 


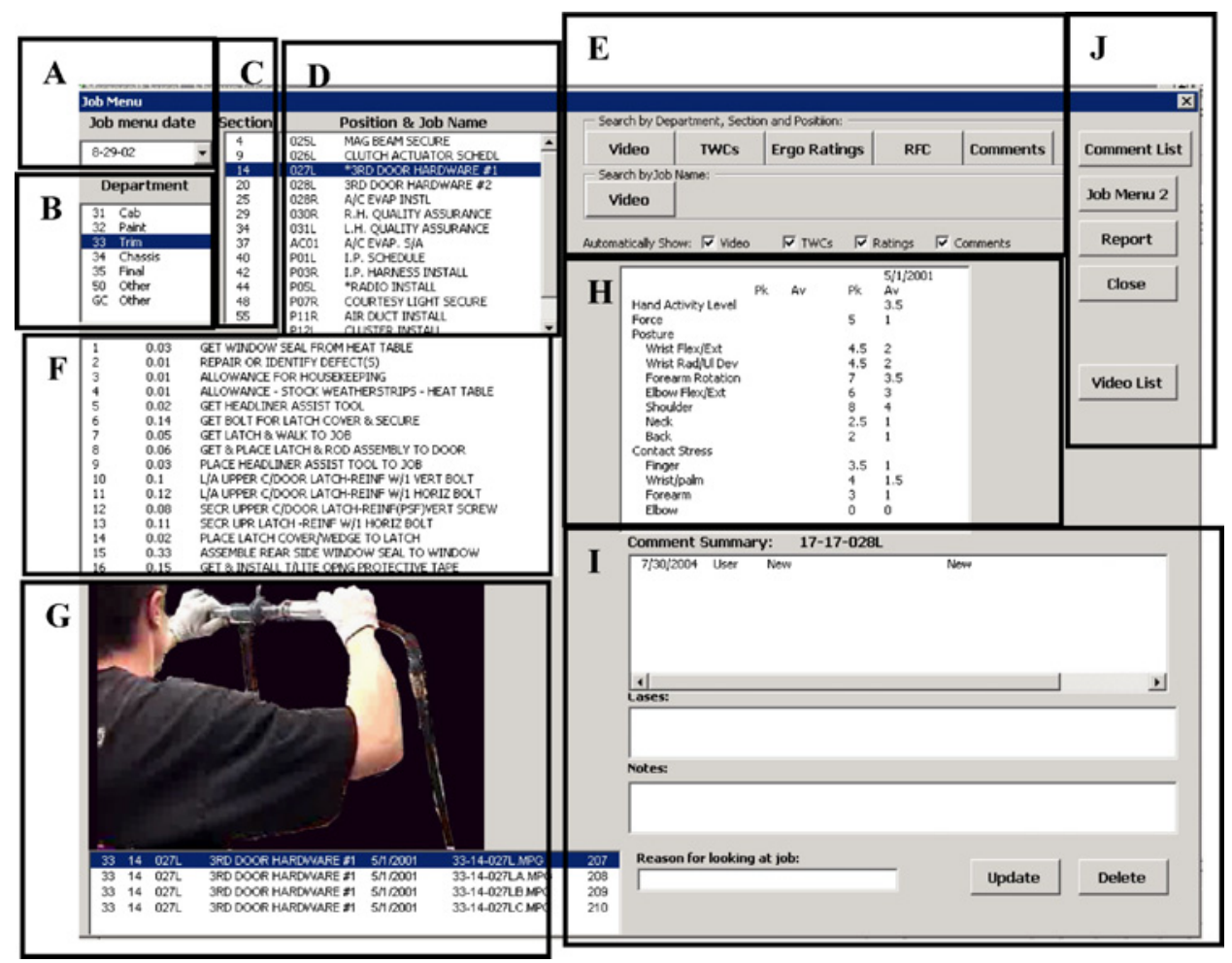

Fig. 2. The graphical user interface used to store and retrieve data with a brief description.

- upper extremity exposure ratings (evaluated by the research team) for repetition, posture, contact stress, and force (adapted from Latko (12) and ACGIH (13)) (see Fig. 2, section $\mathrm{H}$ )

- standard data: work elements (SWE) and times for selected job, obtained from the company standard data system (see Fig. 2, section F)

- text box that allows users to store and retrieve comments about selected job (see Fig. 2, section I)

- menu to search for a job by department, section, line position, and by date (see Fig. 2, sections E and A)

- functionality to spilt window and compare two jobs (specifically, the same job for different time periods) - the archived job information were retrievable based on a time-stamp (see Fig. 2, section J)

- report generator-creates reports in Microsoft Word ${ }^{\mathrm{TM}}$ (see Fig. 2, section J)

The videos were an important part of the database. Videos were digitized and stored in mpeg format to minimize required file space and imbedded into Microsoft Excel ${ }^{\mathrm{TM}}$. An updated electronic standard data file was obtained from the company every 3-4 months and reviewed. In the case of substantial job changes, the jobs were re-rated and videos were updated in the database. 
The database was loaded on a computer in the UMETs' office and the plant physician's office, but the two were not linked. The focus group in the study was the UMETs since they used database as a decision support tool in the control of WMSDs. All three users were trained on the features of the database by the developer. The users who made updates in the comments textbox were monitored since they were prompted to log on at the start of the program.

\section{METHODS}

The goal of this work was to assess the applicability of a computerized decision support system (DSS) in helping ergonomists better match the workers with the work environment. Research methods included extraction and analysis of comments data input into the database by the users, formal interviews, and direct observation.

The comments pertaining specifically to jobs were extracted by the research team and used in the evaluation of the software effectiveness. There were almost 200 comments entered into the database between November 2001 and April 2003. Those comments were reviewed and grouped according to primary versus secondary prevention, the user who made comment, and the type of intervention (if any) recommended. A sample size of three users did not permit sufficient statistical power for rigorous analysis; however, histograms and descriptive statistics were used for analysis.

The other research method used in this study was one-on-one, semistructured interviews designed to capture information that would not be available from the comments in the database. The interview questions were developed to provide two types of data: the impact of the software on the process of evaluation and prevention of risk and the usability of software from the viewpoint of users with varying degrees of computer knowledge. Three UMETs were interviewed over a 2-day period during workhours and informal observations made throughout the course of 3 workweeks. The interview data were collected approximately 20 months after the initial implementation of the software.

Not only were the interviews designed for research purposes, but also for the future software development. The database underwent considerable development during the design phase and the project investigators, who were not onsite, only visited at 3-6-month intervals. During those visits, they would demonstrate and discuss features of the software with the UMETs. They worked closely with the UMETs to train them on the features of the software, as well as get feedback on functionality and interface enhancements. At the request of the users, new features were added to the program such as the report generator, ability to record comments and compare work elements over time, and a tool database linked to the job database.

The interviewer was not involved in the database development so that she would not be biased by the knowledge of system development or outcome. The interviewer in this study was a graduate student with a formal education in Industrial Engineering and work experience in software development.

Of the three UMETs, one member was a management employee with a college degree in Industrial Engineering, while the other two were union members who started with the company as assembly line workers. The union representatives came through the ranks of the company and gained ergonomics experience on the job and through formal training. Each had more than 20 years of experience. There was considerable variation in each UMET's 
computer and software skills. The management UMET regularly used a computer to search the web, send and receive e-mail, access company records, and perform job analyses while one union UMET rarely used this or any computer, and the other used it occasionally. All three were male, aged mid to late fifties, knowledgeable of the job, and committed to the cause of promoting a safer work environment for the employees.

\section{RESULTS}

The interview data will be presented first, followed by the analysis of the comments data. The interview responses from the UMETs were divided into three categories: the temporal conditions, (e.g., frequency of use); the benefits of the tool, (e.g., reduced paper handling); and improvement feedback, (e.g., adding a feature to the interface).

The UMETs reported the time to learn to use the job database was about 1 and 2 days for the regular and occasional users, and 3 days for the infrequent user. This is a relatively short learning curve which suggests that the design of the interface was relatively userfriendly. During the course of the study, the frequency of database use averaged three times per day for the two most experienced users. The users were prompted [but not required] for identification at the start of the program and records of the users that made comment updates were available.

Seventy-three percent of the comments were attributed to the management UMET (see Table I). One reason was that it was informally established that the management UMET would primarily be responsible for entering the cases into the database. The management UMET had prior experience using the company's information management system to track ergonomic injuries. The two union UMETs, however, did not appear to input as many comments because the majority of their evaluation documentation was done using paper files. The least experienced computer user reported he used it only a few times throughout the study because he did not have his own computer with the software loaded, and sometime in the past [before this study] he had "crashed the system" and was then reluctant to use computers. Also, there were some validity concerns with the distribution of comments. It is possible that some of the management UMET's comments were entered by a union technician, but the program defaulted to the user who originally logged on. Finally, $2 \%$ of the comments did not have an ID associated with them.

A summary of the key points from the UMETs' interviews regarding the main features of the software appears in Table II. Each UMET was interviewed separately and the results were grouped into categories in the "Feature" column. Some of the responses were unanimous among the three users, which are indicated by " 3 " in the " $N$ " column. For readability, the positive and negative feedback was separated.

Table I. Distribution of Comments Entered by User $($ Total $=197)$

\begin{tabular}{lc}
\hline \multicolumn{1}{c}{ UMET user } & $\%$ of Comments entered \\
\hline Management & $73 \%$ \\
Union (occasional) & $20 \%$ \\
Union (rare) & $5 \%$ \\
Unidentified & $2 \%$ \\
\hline
\end{tabular}


Table II. UMETs' Summary of the Utility of the Database. "N" Indicates the Number Who Expressed the Comment

\begin{tabular}{|c|c|c|c|c|}
\hline Feature & Positives & $N$ & Negatives & $N$ \\
\hline \multirow[t]{8}{*}{ Job videos } & $\begin{array}{l}\text { 1. Multiple videos are useful. The } \\
\text { variation in body dimensions } \\
\text { [of a different size operator] }\end{array}$ & 3 & $\begin{array}{l}\text { 1. Viewing angles do not always } \\
\text { capture the risk, especially } \\
\text { involving the hands }\end{array}$ & 3 \\
\hline & $\begin{array}{l}\text { adds to the analysis as does the } \\
\text { different angles and the }\end{array}$ & & $\begin{array}{l}\text { 2. Zooming in on risk would be } \\
\text { more helpful }\end{array}$ & 3 \\
\hline & mixed-product job content & & & 2 \\
\hline & $\begin{array}{l}\text { 2. Used to look at posture angles, } \\
\text { and used in conjunction with } \\
\text { the } 3 \mathrm{D} \text { software }\end{array}$ & 1 & $\begin{array}{l}\text { files } \\
\text { 4. The } 1 \text {-min recorded cycle is not } \\
\text { enough on mixed-product }\end{array}$ & 2 \\
\hline & $\begin{array}{l}\text { 3. Used to take measurements on } \\
\text { posture, hands, and angles }\end{array}$ & & $\begin{array}{l}\text { jobs-it doesn't capture all the } \\
\text { tasks }\end{array}$ & \\
\hline & & 1 & 5. All videos are not up-to-date & 1 \\
\hline & & & $\begin{array}{l}\text { 6. All jobs are not included in the } \\
\text { database }\end{array}$ & 1 \\
\hline & & & $\begin{array}{l}\text { 7. No top angle shots which are } \\
\text { useful for the 3D program }\end{array}$ & 1 \\
\hline \multirow[t]{2}{*}{$\begin{array}{l}\text { Comparing job } \\
\text { work elements } \\
\text { from different } \\
\text { times }\end{array}$} & $\begin{array}{l}\text { 1. The ability to compare the past } \\
\text { and current SWEs is an } \\
\text { important function. It is } \\
\text { necessary to see what changes } \\
\text { were made in the job tasks }\end{array}$ & 3 & $\begin{array}{l}\text { 1. The target for updating the } \\
\text { information in the database } \\
\text { should be biweekly rather than } \\
2-3 \text { times per year }\end{array}$ & 1 \\
\hline & $\begin{array}{l}\text { 2. Split window feature useful } \\
\text { when comparing the old and } \\
\text { current SWEs }\end{array}$ & 3 & $\begin{array}{l}\text { 2. The target for updating is when } \\
\text { a job changes }\end{array}$ & 1 \\
\hline Ergonomic ratings & $\begin{array}{l}\text { 1. Useful for reference (though } \\
\text { individual rating is performed } \\
\text { by the UMET) }\end{array}$ & 3 & $\begin{array}{l}\text { 1. Ergonomic stress scale }(0-10) \\
\text { in the database is different } \\
\text { from the company standard } \\
(>1 / 3 \text { cycle and }<1 / 3 \text { cycle }) \\
\text { reduces their usefulness }\end{array}$ & 1 \\
\hline \multirow[t]{2}{*}{ Comments text field } & $\begin{array}{l}\text { 1. Allows easy viewing of the } \\
\text { other UMET members' } \\
\text { comments }\end{array}$ & 1 & $\begin{array}{l}\text { 1. Cannot view both the video } \\
\text { and the comments at the same } \\
\text { time from the job compare } \\
\text { screen }\end{array}$ & 2 \\
\hline & $\begin{array}{l}\text { 2. Comments field tells the } \\
\text { actions taken }\end{array}$ & 1 & & \\
\hline Report generator & $\begin{array}{l}\text { 1. The feature is useful and } \\
\text { format is okay but it has not } \\
\text { been used }\end{array}$ & 2 & $\begin{array}{l}\text { 1. Cannot easily generate reports } \\
\text { of open issues with job IDs, } \\
\text { nor download issues into EMS }\end{array}$ & 1 \\
\hline
\end{tabular}

Overall, the UMETs were supportive of the new system because it improved the efficiency and quality of the ergonomic job evaluation process in ways (see Table III) that will be discussed in the Discussion Section. They also reported that the feature most favored and utilized was the functionality to compare work elements from different times, which enabled them to quickly identify job changes and assess its impact on the worker. The management UMET described a situation in which a worker incurred a back injury subsequent to a change in the placement of parts.

A woman working on the assembly line had injured her back. We evaluated the job by direct observation using the Risk Factor Checklist. During the ergonomic analysis, we used the job database to search for recent job changes and found none. It turned out that the location of incoming parts was changed - the skillet height was lowered 10 inches. This resulted in the worker increasing the magnitude of her bending when reaching for parts and that eventually led to her low back pain. When we compared the placement of parts in the video to the poor placement of 
Table III. Summary of How the Database Adds Value and Supports Plant Ergonomics (Based on UMET's)

\begin{tabular}{|c|c|c|}
\hline Value of tool & How value is added & $N$ \\
\hline \multirow[t]{5}{*}{ Streamlining the process } & 1. Reduction in the amount of paperwork & 3 \\
\hline & 2. Electronic tracking of the history of job changes & 3 \\
\hline & 3. It can be used as a training tool for the new operators & 1 \\
\hline & $\begin{array}{l}\text { 4. Less time is spent on plant floor and a reduction in the } \\
\text { number of trips to the floor }\end{array}$ & 1 \\
\hline & $\begin{array}{l}\text { 5. The industrial engineers can have faster access to all the jobs } \\
\text { and the task times. Alternatively they must get job } \\
\text { information on the plant floor. }\end{array}$ & 1 \\
\hline \multirow[t]{4}{*}{ Improving the quality of analyses } & $\begin{array}{l}\text { 1. The ratings are useful references during the evaluation of risk } \\
\text { factors. }\end{array}$ & 3 \\
\hline & 2. The videos are useful for discussion of risk factors & 3 \\
\hline & $\begin{array}{l}\text { 3. Allows for collective (team) analysis of the ergonomic risks, } \\
\text { privately rather than publicly (reduces the discussion of the } \\
\text { job as much in front of workers) }\end{array}$ & 2 \\
\hline & $\begin{array}{l}\text { 4. The doctor can look at the video and help in the analysis of } \\
\text { restriction and worker replacement }\end{array}$ & 1 \\
\hline
\end{tabular}

parts at the workstation, we noticed a difference in skillet height. Our recommendation was to raise the skillet height to reduce the severe bending. The job database was useful in that it enabled us to identify job changes and it provided the visual evidence of the difference in [WMSD] risk factors.

\section{Addressing the Limitations of the Tool}

Though the benefits of the job database were evident, the UMETs also reported how they thought it could be improved. The limitations of the software in evaluating jobs were not only captured in some of the items in the "Negatives" column of Table II, but also in Table IV which summarizes their suggestions for improvement.

All recommendations (Tables II and IV) made by two or more UMETs could be grouped into two areas: 1) user control, that is, the ability to update the jobs and videos on their own, and 2) information sufficiency, the addition of more detailed job data required for thorough job evaluations. Both of these categories lead to building better practices and capability in evaluating ergonomic risks.

To address the first recommendation, the UMETs were provided with digital cameras that enabled them to record job videos in mpeg format that can be uploaded directly into the computer. The next step will be to modify the software program so that the videos can be linked to jobs in the database.

To address the next recommendation, adding more detailed job information such as tool and part information, required collecting the information from the company's standard data system and entering it into the database comment box. Adding the functionality to compute NIOSH indices was a coding modification being tested during the interview period.

Other suggestions included purchasing portable hardware technology (i.e., hand-held PCs) which would enable the UMETs to travel throughout the plant with the database. The researchers experimented with the use of personal data assistants, but displays were found to be inadequate. Later in the study, notebook computers became available and they showed great promise. 
Table IV. Summary of UMET's Suggestions for Improving the Database

\begin{tabular}{lll}
\hline \multicolumn{1}{c}{ Action } & \multicolumn{1}{c}{ Items } & $N$ \\
\hline Add more job & 1. Tool torque data & 2 \\
information & 2. Material and parts weight & 2 \\
& 3. PPE and tools required & 2 \\
& 4. Force required for pushing and pulling on the job & 1 \\
& 5. Column location number (the physical address) & 1 \\
Add updating & 1. Video adding and deleting capability & 2 \\
capability & 2. Work element updating capability & 1 \\
Improve the & 1. Zooming in on the risk factor & 3 \\
usefulness of the & 2. Adding the ability to calculate the NIOSH Action Limit for lifting & 3 \\
videos by & 3. Adding a running clock to supplement the video & 2 \\
& 4. Increasing length of the video or add video which captures the various & 1 \\
product types & 1 \\
Add capability to & 5. Adding videos that capture irregular jobs & 1 \\
interface with other & 6. Including top angle shots which are useful for the 3DSSP program & 1 \\
software & 1. Link the new database comments to EMS & 1 \\
Add portability & & 1. Need to take the database on the plant floor (using a portable computer) \\
Add text field & 1. Need a field that identifies the ergonomic risk factor associated with & 1 \\
& medical cases
\end{tabular}

The next set of results shift focus from how the process [of evaluating and controlling injuries] was changed with the implementation of the database, to what primary and secondary preventions were implemented to control WMSDs. These data are based on the 197 comments entered into the database during the study period and give insight into how the tool was used to track ergonomic issues over time.

The extracted user comments were divided into two categories determined by type prevention. The first category of comments addresses primary prevention of WMSDs- that is, the UMET recorded in the database an ergonomic evaluation, intervention, or follow-up even though no worker injury occurred. In these instances, a request to evaluate a job could come from a worker, supervisor, or union representative. The second category of comments addresses secondary prevention, that is, the UMET recorded in the database injury and medical evaluation results. Of the 197 comments entered between November 2001 and April 2003, 23\% were issues related to primary prevention and $77 \%$ related to secondary prevention. Figure 3 shows the trend of the number of new comments entered into the database.

The initial trend in the number of primary preventions was promising because it suggests that the UMETs were working toward preventing initial injuries and logging the work in the database. Without the actual number of injuries reported to medical (the data was not available), it is difficult to do a direct comparison of primary and secondary preventions and/or a comparison of actual cases versus cases reported in the database. What is important is the upward trend in use of the database over time suggesting it was a useful tool. The use of it curtailed in July and August 2002 due to a plant shutdown and a shift in vehicle production from the current facility to a new one. During the transition to the new plant, the UMETs were called to address ergonomics in the new plant and since the database was not populated with any of the new job data the software was of no practical 
New comments entered monthly

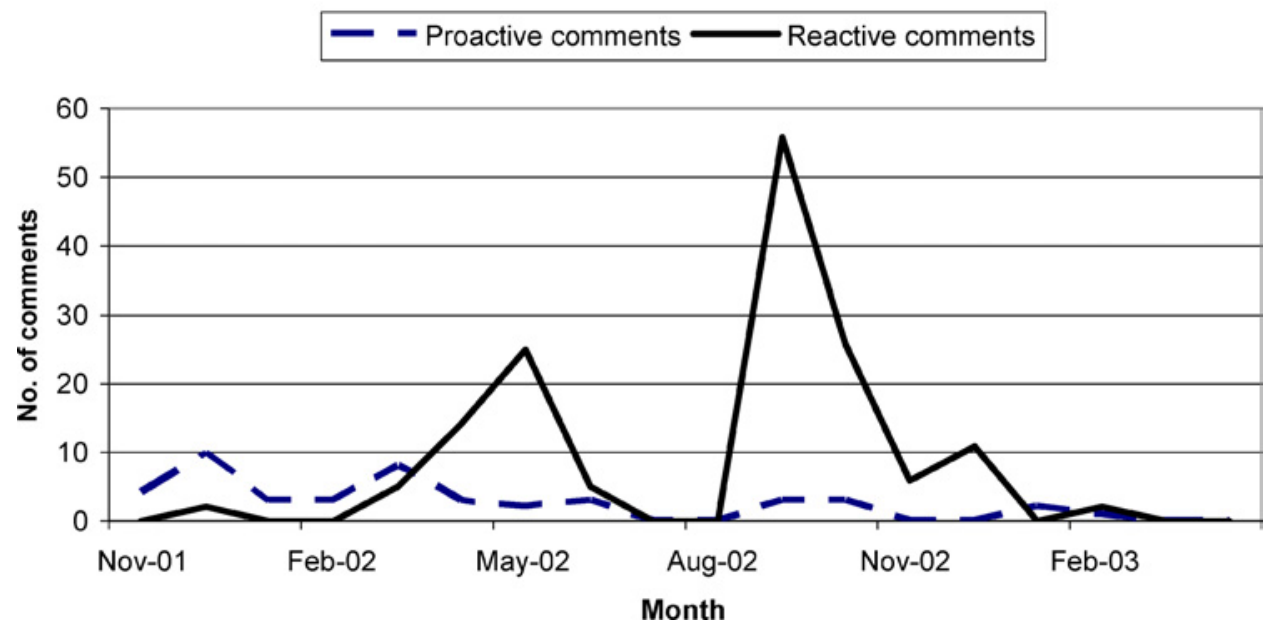

Fig. 3. New comments entered per month from November 2001 to April 2003.

use. Likewise, after September, the new facility shifted the company's focus and resources away from the older production line and the UMETs' use of the software eventually ended in 2003. Had the use of the software continued, it would have been ideal for the trend of proactive comments increase at a higher rate suggesting that primary prevention was increasing over time, however, the proactive and reactive patterns were relatively consistent during the study period.

Information typically reported in the database by the users was the type of injury (e.g., shoulder strains, thumb sprains, etc.), the medical case number, and a brief explanation. Table $\mathrm{V}$ lists several examples of the typical entries found in the database. Most are of the format: "date/injury report \#/explanation" which states the issue, followed by the intervention.

The format of the first two rows in Table V was the majority format (124 out of 197, or $63 \%$ of comments) and largely entered under the management UMET's login ID. The remaining comments had no standardized format and pertained to a wide range of job aspects such as: a listing of the tool or part numbers required for the job, the operator's comments regarding the injury or complaint, the results of a preliminary investigation, whether (or

Table V. Examples of the Types of Comments Entered in the Database

\begin{tabular}{ll}
\hline \multicolumn{1}{c}{ Ergonomic issue reported } & Intervention \\
\hline 08-14-02/123456/Sprain bilateral hands/pain was from & Leather gloves issued \\
striking lights to grill & Swivel arm removed \\
09-09-02/ 987654/Strain right shoulder & No ergonomic risk factors noticed \\
10-15-02 Operator stated pain in left shoulder is due to & \\
old injury from 15 years ago & \\
04-22-02-PRO-ACTIVE-Purchase battery tool to eliminate & \\
finger starting four bolts. & \\
\hline
\end{tabular}


Table VI. Example of UMET's Tracking an Issue Over Time (10 weeks)

\footnotetext{
Comments: Job 35-14-006 Instrument panel

11-12-01 Engineering M. Terry stated tooling will start working on project 11-16-01.

12-04-01 Engineering M. Terry has new controls for hoist. Will schedule to be installed. No tentative date?

12-13-01 Terry stated hoist will be installed by week ending 12-16-01.

1-21-02 The plant was down for 4 weeks and assist has not been installed.

2-01-02 The end effector has been installed. Second-shift employee trained for 2 days on first shift. Swivel ordered for tool.
}

not) the issue was ergonomic, the status of the ergonomic control to be implemented, and in some cases, the person responsible for the fix.

Another important aspect of the database was the ability to track issues over time and the potential for a reduction of lost cases during follow-up. Table VI is an example pulled from the database that demonstrates the tracking of an intervention to closure. Each date/column represents a new comment.

The next set of results, Tables VII and VIII, pertain to the types of ergonomic interventions that were reported in the database for primary and secondary prevention.

- The total number of the interventions discussed is 122 (43 primary and 79 secondary).

- Of the primary intervention comments (see Table VII), 55.6\% were interventions associated with an ergonomic risk, while $40 \%$ (or 18) were updates to a previously recorded case, and $4.4 \%$ (or 2) were reports of an ergonomic problem with no corrective action mentioned.

- Of the secondary intervention comments, 52.6\% had an associated intervention, while $34.2 \%$ (or 52) were injury reports with no intervention mentioned, and $13.2 \%$ were injuries with no ergonomic risk factors found during the evaluation.

There are several reasons that some of the cases were recorded without an intervention: 1) the problem was considered nonergonomic and the UMET did not comment on it 2) the ergonomic problem was not noticeable during the actual evaluation-for example, the same or new operator did not experience the same problem on the job 3) the problem was caused by a lack of training and assumed to improve in time 4) some problems did not require a detailed job analysis and were fixed without being entered into the database and 5) The diagnoses were not always clear.

Table VII. Interventions Reported for Primary Preventions (Total Comments $=45$ )

\begin{tabular}{lrc}
\hline \multicolumn{1}{c}{ Category } & $N$ & $\%$ of total \\
\hline Material handling device added & 6 & 13.3 \\
Tool changed (improved) & 5 & 11.1 \\
Workstation layout changed & 4 & 8.9 \\
Tool balancer installed & 3 & 6.7 \\
Floor mats installed/replaced & 3 & 6.7 \\
Tool repaired/adjusted & 2 & 4.4 \\
Work methods changed & 1 & 2.2 \\
Part quality improved & 1 & 2.2 \\
Updated a previous comment/issue & 18 & 40.0 \\
Report only-no intervention mentioned & 2 & 4.4 \\
\hline
\end{tabular}


Table VIII. Intervention Reported for Secondary Preventions (Total Comments = 152)

\begin{tabular}{lrr}
\hline \multicolumn{1}{c}{ Category } & $N$ & $\%$ of total \\
\hline Personal protective equipment added & 17 & 11.2 \\
Tool changed (improved) & 10 & 6.6 \\
Worker was replaced & 8 & 5.3 \\
Tool repaired/adjusted & 8 & 5.3 \\
Workstation layout changed & 6 & 3.9 \\
Trained worker on work methods & 6 & 3.9 \\
Material handling device added & 5 & 3.3 \\
Work methods changed & 3 & 2.0 \\
Part quality improvement & 3 & 2.0 \\
Housekeeping & 3 & 2.0 \\
Floor mats installed/replaced & 2 & 1.3 \\
Other (process improvement, machine protection added, & 9 & 5.9 \\
$\quad$ exercise recommended, issue update) & & \\
No ergonomic factors found & 20 & 13.2 \\
Reported injury only—no intervention mentioned & 52 & 34.2 \\
\hline
\end{tabular}

Some examples of the comments pertaining to the interventions in Tables VII and VIII include:

- Material handling devices: 1) a roller rack install subsequent to a sprain caused by bending for parts 2) a container modification subsequent to a strained wrist caused when retrieving parts 3) a proactive hoist install used to transfer parts (risk unidentified).

- PPE: 1) leather gloves issued for a hand sprain due to repetitive pressing 2.) shoe inserts and ankle supports issued subsequent to a walking injury (risk unknown) 3.) a thumb protector issued for a thumb sprain due to repetitive pressing, and an arm protector issued for an arm contusion (risk unidentified).

- Workstation (adjustment) layout: 1) a 12" table raise to eliminate excessive bending 2) a revision in platform [height]

- Tool change requests: 1) add lighter weight tool 2) purchase of a battery operated tool 3) install correct tool

In summary, the comments in the database were used to give insight into how the tool was used to track information on primary and secondary MSD prevention issues. The trend of database use was promising while the UMETs were actively resolving ergonomic issues in the old facility. The majority of the secondary and primary cases had an associated intervention, and the range of interventions included both administrative and engineering controls. However, there was still room for improvement in tracking information since $34 \%$ of the injury cases and $4 \%$ of the primary prevention cases had no associated interventions. And finally, the format for inputting data was relatively standardized which is appropriate for long-term efficiency.

\section{DISCUSSION}

The Job Database was intended to be a computerized decision support tool to aid in the prevention of work-related musculoskeletal disorders. Based on its use within the 20-month study period, we can draw some preliminary conclusions about its usefulness, effectiveness, and applicability in labor-intensive work environments. 
The DSS software was useful to the extent that it streamlined the process of proactively and reactively monitoring and evaluating ergonomic problems; in other words, inefficiencies were removed from the process (see Table III). This streamlined process led to a time savings that could be re-directed to addressing more primary prevention cases and follow-ups. The software also facilitated the improvement of the quality of the job analysis by allowing the users to perform a preanalysis and providing job information not previously available. This improvement in quality can lead to better intervention and control of MSD problems.

Compared to the initial process model in Fig. 1, the number of nonvalue adding tasks in the new evaluation model was reduced, specifically step 5, search and get the history of job, had been eliminated. According to the management UMET, it took roughly $1-1.5 \mathrm{~h}$ to gather historical job information. By using the database, the UMETs were able to quickly and easily collect useful information, such as the history of job changes and standard job information (e.g., standard work elements), after an ergonomic issue arrived from medical or a worker. In the previous model, the UMETs also incurred a considerable amount of traveling between the plant floor, industrial engineering office, and other sources to gather information. One union UMET noted that he would often repeatedly travel to and from the plant floor because of a forgotten item in the Ergonomics office (see Table III) and in such a large facility ( 2.1 million square feet), traveling could be time-consuming. Furthermore, prior to the implementation of the database, the UMETs would have to wait until the production line was up and running and the worker was available before they could interview and evaluate the job from the plant floor-adding to process waste. Using the database, they could begin the analysis as soon as the problem arrived.

Though no quantitative data are available for time savings resulting from a reduction in wasteful tasks, the reduction in the number of steps would realistically lead to a reduction in time to perform the overall job evaluation. The company standard is to evaluate ergonomic problems within a couple of months; by using the tool, identification and investigation of high-exposure jobs could be performed much sooner.

While there were no quantitative data to measure the change, reasonable conclusions can be drawn about the direction (positive vs. negative) of impact the tool had on the quality of the ergonomic evaluations. We examine the change in quality in terms of the change in the evaluation process.

In the case of primary prevention, the software tool allowed the UMETs to investigate jobs prior to interviewing the worker or venturing to the plant floor-they could perform a preanalysis, or investigation in preparation for the actual analysis. This was done using the videos to observe job requirements at a micro [motion] level; viewing the comments to see if there were any previous problems on that particular job (see Table II); and viewing the standardized work elements for a description of the standard job tasks. Once the UMET(s) were ready to perform the worker interview and observation, they would check if any standard job characteristics (e.g., work elements, PPE, allowances, etc.) were inconsistent with their live observation. According to the UMETs, these changes or inconsistencies were a good indication of what helped cause the problem. Before there was the database, paper files were used to track job changes, but the reliability and/or availability of these files were considerably lower. In sum, the tool helped improve the process by preparing the UMETs for the job evaluation.

The database also helped improve the quality of the job analyses by providing upper extremity repetition, force, posture, and contact stress ratings $(12,13)$ not previously available. The UMETs were able to use these ratings as a reference to help resolve instances 
of disagreement and/or uncertainty on degree of risk exposure (see Table III). One UMET expressed that there were differences in exposure classification schemes (see Table II) between the database and the company's primary evaluation tool, the Risk Factor Checklist (RFC) (11). The RFC measures the frequency of preclassified risks (e.g., bending more than $45^{\circ}$, reaching behind the torso, etc.) based on a "more or less than a third of the cycle" scale while the ratings in the database are a measure of peak and average exposure levels for upper-extremity repetition, force, posture, and contact stress based on a 10-point scale (12). Repetition was the only risk factor appearing on both evaluation tools in which case the 10-point scale could be mapped in thirds, while the other exposure ratings were used as supplemental information in the job analysis.

Finally, the database also helped improve the quality of the job analyses through the use of video analysis - the job videos were an integral part of the software's utility. Video recording has been a valuable tool in work design measurement since the early part of the past century because it enables observations of motions that would be difficult to catch with the human eye (14). It was often impractical to observe the worker's motions at the level of detail attainable with the video, so the UMET found this feature of the software useful (see Table II) for performing detailed analyses, especially since they were able to stop, enlarge, and repeatedly observe the worker's motions. The extent to which this improved the analysis was not measured during the study period, but at least one UMET stated the videos were used to observe and measure posture angles.

How can this type of technology continuously improve primary and secondary prevention of WMSDs? Continuous improvement is a process that attempts to preserve and build on past improvements: the processes, equipment, and methods are continually changing in today's modern automobile assembly plants. Persons who specify product design, materials, tools, and methods are often removed from the day-to-day operations of the plant. As a result, they may not receive feedback about ergonomic problems and fixes. Also, knowledge capital is lost with employee turnover-knowledge of best practices and fixes for common problems. The Job Database created a centralized source of technical information and best practices that was available to the plant ergonomists, physician, engineering, and maintenance personnel - the entire team of people responsible for primary and secondary prevention of WMSD disability.

Adler et al. (15) describes how ergonomic problems and injury rates at New United Motor Manufacturing Inc. (NUMMI), a joint venture between Toyota and General Motors, were drastically reduced from one model line to the next through their process of continuous improvement. In his conclusion, the countermeasures management used to reduce ergonomic injuries included leadership's review of "lessons learned" from the previous production model and improved methodology for performing ergonomic evaluations. The decision support software in this study served both of these functions, and this same technology could be adapted to other facilities that have similar work patterns within and outside of the automotive sector.

\section{RECOMMENDATIONS FOR FURTHER STUDIES}

While preliminary conclusions can be drawn from this qualitative assessment of the decision support system, a future study should aim to quantify the extent of the time savings and improvement in quality of analyses, as well as evaluate the impact of the 
recommended software changes. Also, an investigation of how the team approach (e.g., physician, ergonomists, workers, etc.) to addressing worker disability and placement is affected by the online use of this centralized source of information would prove valuable.

\section{CONCLUSION}

As a matter of data management, the storage and retrieval of ergonomic information is perhaps the cornerstone to continuous improvement of safety, health, and disability management. Systematic job analysis at the micro level (e.g., work elements and motions) is necessary for the improvement of jobs and development of accommodations for workers with limitations. Since the analysis of work methods is standard procedure for engineering safe work, we need to have ready access to vast amounts of detailed job data. This might also be a promising direction for decision support systems and the use of spreadsheetbased software to facilitate knowledge management and increase information utilization. Since Microsoft Excel ${ }^{\mathrm{TM}}$ is already widely used across many corporations (9); it may be worthwhile to explore such tools.

\section{ACKNOWLEDGMENTS}

This project was funded in whole by joint funds from the UAW-GM National Joint Committee on Health and Safety. The results presented herein represent the conclusions and opinions of the authors. Its publication does not necessarily imply endorsement by the International Union, UAW, or General Motors Corporation.

\section{REFERENCES}

1. Bureau of Labor Statistics. Lost work-time injuries and illnesses: Characteristics and resulting time away from work, 2002. Washington, DC: Bureau of Labor Statistics, U.S. Department of Labor, 2002. Retrieved February 24, 2005 from http://www.bls.gov/iif/oshcdnew.htm

2. Bernard B, ed., Musculoskeletal disorders and workplace factors: A critical review of the epidemiological evidence for work-related musculoskeletal disorders of the neck, upper extremity, and low back. Cincinnati, OH: U.S. Department of Health, Education, and Welfare, Public Health Service, Centers for Disease Control, National Institute for Occupational Safety and Health, 1997.

3. National Research Council and Institute of Medicine. Musculoskeletal disorders and the workplace: Low back and upper extremities, Panel on Musculoskeletal Disorders and the Workplace Commission on Behavioral and Social Sciences and Education National Research Council and Institute of Medicine. Washington, DC: National Academy Press, 2001.

4. Gilbreth F, Gilbreth L. Motion study for crippled soldiers: A paper presented at a meeting of the American Association for the Advancement of Science, Columbus, OH, December 27, 1915. In: Spriegel WR, Myers CE, eds. The writings of the Gilbreths. Homewood, IL: R. D. Irwin, 1953, pp. 281-288).

5. Bridges C. Job placement of the physically handicapped. New York: McGraw-Hill, 1946.

6. Alexander D. The practice and management of industrial ergonomics. Englewood Cliffs, NJ: Prentice-Hall, 1986.

7. Weisman G. Rehabilitation engineering in the workplace. In: Smith R, Leslie J, eds. Rehabilitation engineering. Boca Raton, FL: CRC, 1990, Chap. 12.

8. Armstrong T, Franzblau A, Haig A, Keyserling WM. Developing ergonomic solutions for prevention of musculoskeletal disorder disability. Asst Technol 2001; 13: 78-87.

9. Palocsay S, Markham I. Teaching Spreadsheet-based decision support systems with Visual Basic for applications. Inf Technol Learn Perform J 2002; 20(1). 
10. Ragsdale CT. Teaching management science with Spreadsheets: From decision models to decision support. INFORMS Trans Educ 2001; 1(2): 68-74.

11. Keyserling WM, Stetson DS. A checklist for evaluating ergonomic risk factors associated with upper extremity cumulative trauma disorders. Ergonomics 1993; 36(7): 807-831.

12. Latko W, Armstrong T, Foulke J, Herrin G, Rabourn R, Ulin S. Development and evaluation of an observational method for assessing repetition in hand tasks. Am Ind Hyg Assoc J 1997; 58: 278-285.

13. ACGIH. Hand activity level, two thousand two TLV for chemical substances and physical agents and biological exposure limits. Cincinnati, OH: American Conference for Governmental Industrial Hygienists, 2004.

14. Barnes R. Motion and time study: Design and measurement of work. New York: Wiley, 1968.

15. Adler P, Goldoftas B, Levine D. Ergonomics, employee involvement, and the Toyota production system: A case study of NUMMI's 1993 model introduction. Ind Labor Relat Rev 1997; 50: 416-437. 